\title{
A Critique on the Role of Social Media; Facebook
}

\author{
M. K. Dinithi Padmasiri ${ }^{1}$ and M. D. Pubudu Kawshalya ${ }^{2}$ \\ ${ }^{1}$ Department of Human Resource Management, University of Kelaniya, Sri Lanka \\ ${ }^{2}$ Department of Accountancy, University of Kelaniya, Sri Lanka \\ ${ }^{1}$ dinithipadmasiri@kln.ac.lk, ${ }^{2}$ pubuduk@kln.ac.lk
}

\begin{abstract}
This literature review reviews various roles of Facebook (FB) are playing in today's globalized world. According to literature, Facebook plays roles in various fields such as, marketing, online games, education, teaching, romantic relationship management, managing relationship among friends, and stakeholder engagement. The current study limits its investigation in to selected roles of Facebook such as academic teaching, marketing and romantic relationship management. One finding of the stated that using blogging tools to further develop relationships with undergraduate and graduate students and engage them in meaningful discussions outside of class time. According to another studies Facebook plays a major role in romantic relationship management which creates emotional outcomes as relationship satisfaction and trait jealousy. Further literature argues that network is important in changing the way of business talk with customer and indicates that Facebook plays a role as a communication channel in marketing at business level. Review discussed that FB plays important roles such as, FB in academic teaching, FB in marketing, and FB in romantic relationship. Based on above discussion study can conclude that Facebook plays an important role in various fields.
\end{abstract}

Keywords: Roles, Facebook, Teaching, Marketing, Romantic Relationship

\section{Introduction}

Web 2.0 is the most current state of online technology and when it compares with the traditional online technologies, it has some interesting characteristics like user interactivity, collaboration, more pervasive network connectivity and enhanced communicational channels (Bullock, 2011). Especially because of the greater collaboration among internet users, content providers and enterprises, once the original data was posted on web 
sites, users simply view and download the content. Further users have more input into the nature and scope of Web content and in some cases exert realtime control over it. Because of this social nature in Web 2.0, it has enhanced the social networking and therefore number of social contacts has been established by making connections among individuals through number of social networking sites include Facebook (FB), Twitter and LinkedIn. Facebook started out as a site for sharing pictures and chart among college students but has evolved into a significant platform for businesses. Facebook provides a way for families and friends to stay in touch and share their daily lives and pictures. It also allows to create business pages that are separate from the personal page. Major advantages of Facebook include its availability to chosen universities, polytechnics, colleges of education, research institutes and lots more and the high level of society associated with the platform; and the opportunity it offers users to check students who are in the same class, living within the same location or coming from the same academy.

Facebook as a Social Media (SM) include but are not limited to the following: (1) It involves more and more people (crowding); (2) Long distance relationship weakening; (3). Unsupported by physical adjacency; (4) Contributes to wide range procrastination; (5) Creates terrible addiction; (6). Possible stalking; (7). Acquaintances labeled as friends; (8) Contributes to poor academic performance of students (especially among heavy users); (9). Harbors criminals and facilitates criminality; (10) Facilitates immorality among youths; (11) Occasions physical harm or death. But in this study investigates beneficial roles of FB to todays' context like marketing, online games, education, teaching, romantic relationship management, managing relationship among friends, and stakeholder engagement (Beukeboom, 2011); (Bonsón, 2013); (Bullock, 2011); (Scolbe, 2006).

\section{Facebook in Academic Teaching}

As mentioned in above paragraphs teaching means in this study is academic teaching. Academic field is not escaped from the ways in which society and culture are changing as a result of new digital technologies. There are numerous research are devoted to exploring the various intersections of technology and education (Bullock, 2011). 
The current study's first archive is FB in academic teaching. For various reasons, and not only because it is the most popular one, Facebook stands out among virtual social networks (Taverner, 2015). In FB, users are the owners of their own space and also of their profile (Llorens-Cerdà, 2011). FB may become a tool not only to relax-since social networks usually represent an activity associated with free time and low stress levels-but also to help students learn and educate themselves simultaneously (Taverner, 2015). According to the same study's discussion, FB can actually be used to perform the same type of functions that were already carried out by other ICTs, such as communicating students with one another, or with their teacher, receiving announcements or updates, and also managing projects and collaboration schemes outside the classroom. FB develops a greater motivation to students' teach (Mahmud, 2012).

Today FB is familiar and feels as ease using to many students and popular in academic filed not only among students but also academia. In the study done by (Taverner, 2015) showed four strengths of FB in academic teaching namely communication, participation, motivation and performance. As cited by above researcher (Wang, 2013) said FB is a means to exchange information or, expressed differently, for communication. Participation is additionally made easier because it represents a good way to communicate between students who are bashful or shy, it helps them to lose their inhibitions, and they can participate more openly than face to face (Omar, 2012). Taverner (2015) cited (Wang, 2013) where researcher showed from the academic point of view, the utilization of FB at universities significantly improves the motivation to learn as well as the learning atmosphere in the classroom, and it improves the relationship between teachers and students too. In the same way Taverner (2015) cited previous study and explained both lecturers and students have as our priority interest to improve students' performance as well as their academic outcomes and although a number of studies have been written about the use of FB. In the same study expressed FB connection with learners' academic performance, no categorical results have been obtained, mainly because most of these studies did not focus on the use of Facebook for academic or learning purposes but simply analyzed which students used Facebook and which ones did not, along with their academic performance-and very often those who were regular FB users devoted fewer hours to study. 
In other words, not many research works have so far dealt with the utilization of FB as part of the curriculum or of the way to teach students. FB improves interaction, which turns out to be an essential element required both for the knowledge acquisition process and for cognitive and physical development. Bringing FB and teaching together make it possible to break the four walls of a classroom and gives students a place where they can interact with one another in order to effectively improve their learning (Halawati, 2013).

\section{FB in Marketing}

As cited by Escobar-Rodríguez, 2015, Li, 2005; Mangold and Faults, 2009; Men and Tsai, 2013 said social media are changing the communication strategies of companies because they facilitate a more dynamic and interactive way to communicate that is leading to larger stakeholder engagement. Therefore researchers attempt to find another role of FB in marketing.

Companies may use SM platforms such as Facebook, Twitter and YouTube to interact with their stakeholders by establishing a two-way communication protocol (Bonsón, 2013). As cited by (Bonsón, 2013) , Hsu (2012) conducted a qualitative investigation of the current use of $\mathrm{FB}$, as an international e-marketing tool, based on its usage by six large luxury hotels in Taiwan. That researcher concluded Chinese language as a limiting factor in spreading the message virally to international leisure travelers and suggests that the use of other language support options can enhance hotels' international e-marketing via Facebook. Even those findings are limited to such case but through findings in general we can understand that FB plays a major role in corporate level.

In another research conducted by (Dholakia, 2010) again proved FB plays a role in corporate level by creating a FB page to promote a bakery and coffee chain and find that once customers became Facebook fans they increase their visits to the facilities and generate more word-of-mouth than non-FB fans. And as cited by (Bonsón, 2013) Gil-Or (2010) reported that on a restaurant FB page positively affects the number of fans. (Lee, 2012) found stakeholders' emotions exhibited on FB have a significant impact on the 
perceived usefulness, perceived ease of use and perceived enjoyment of such SM marketing.

(Bonsón, 2013) found Spanish hotel chains are using FB as a communication and engagement channel, larger hotels are more active and receive wider audiences, the information they post is mainly addressed to current or potential customers, most users' comments to posts are positive, regarding engagement, there is a significant negative relationship between the size of the hotel chain and audience and activity and finally, there is a significant positive relationship between engagement level and post content as well as with media type. These findings indicate that hotel chains typically use FB as a communication channel that is addressed to customers that show a greater degree of engagement. Therefore, again it has proved FB plays a role in marketing at business level.

\section{FB in Romantic Relationship}

Relationship refers to a connection, association or involvement, emotional or other connection between people. It is a state of affairs existing between those having relations or dealings (Webster, 2013). In the case of romantic relationship seeing that the romantic partner leaves comments on the FB wall of an attractive member of the opposite sex can induce jealousy (Muise, 2009). And that same researcher emphasized brought the attention to a negative effect FB use might have: increasing jealousy. In the same study elaborated that people can become jealous if they see their partner interacting with potential romantic partners on FB.

As cited by (Beukeboom, 2011) Zhao et al. (2008) reported that FB users express their affection to loved ones on their profiles and (Beukeboom, 2011) presented that the partners are happy about this public display of affection.

According to David (2010) one of the major reasons why relationships fail is poor communication. This observation by the authors reinforces the central role which communication play in any healthy relationship. The other reasons the writers point out include: lost that loving feeling, financial problems, lack of time, sexual issues, marrying too young, loss of respect and admiration, opposites attract and butt heads, poor boundaries with extended family, and substance and alcohol abuse. Moving to the FB in 
romantic relationship concept some of above reasons advanced by above authors also account for high mortality rate of FB relationships.

Beukeboom (2011) showed that FB users are much more likely to be happy about the publicly displayed affection of their partner than to become jealous. However, the amount of information, the socially accepted way of monitoring the partner and the public display of potentially jealousyinducing events can lead to negative experiences, especially among lowself-esteem individuals with a high need for popularity. Based on the above discussion another factor of this study has established as FB plays a role in romantic relationship.

\section{Conclusion}

Main objective of the study was review literature related to roles of FB. Through investigation identified in FB plays a role in marketing, online games, education, teaching, romantic relationship management, managing relationship among friends, and stakeholder engagement. Todays' academic field is dealing with digital technologies and there are numerous researches are devoted to exploring the various intersections of technology and education.

FB can actually be used to communicating students with one another, or with their teacher, receiving announcements or updates, and also managing projects and collaboration schemes outside the classroom and leads to greater motivation to students' learn. Further discussed FB is in academic teaching namely communication, participation, motivation and performance.

Companies may use Facebook to interact with their stakeholders by establishing a two-way communication protocol and basically with customers as marketing tool. Finally, indicate that FB plays a role in marketing at business level. Previous studies elaborated in romantic relationship FB creates emotional outcomes such as happy and jealous. Therefore, researchers can elaborate that FB is important SM which plays major role in todays' world. 


\section{Reference}

Beukeboom, S. U. (2011). The Role of Social Network Sites in Romantic Relationships: Effects on Jealousy and Relationship Happiness. Journal of Computer-Mediated Communication, 511-57.

Bonsón, E. a. (2013). A set of metrics to assess stakeholder engagement and social. Online Information Review, 37(5), 787-803.

Bullock, S. M. (2011). Teaching 2.0: (re)learning. Education, Interactive Technology and Smart, 94-105.

David, L. V. (2010). 10 reasons relationships fail, Loss Angeles Therapy Group Articles base. Retrieved from http://m.article base.com/relationships-articles/10-reasons-relationship-fail-and-howto-succeed.

Dholakia, U. (2010). One café chain's facebook experiment. Harvard Business Review, 88(2), 26.

Halawati, A. (2013). The integration of authentic learning principles and facebook in service learning. The Turkish Online Journal of Educational Technology, 12(4), 192-199.

Lee, W. X. (2012). The effect of facebook users' arousal and valence on intention to go to the festival: applying an extension of the technology acceptance model. International Journal of Hospitality Management, 31(3), 819-827.

Llorens-Cerdà, F. (2011). Facebook's potential for collaborative e-learning. Revista de Universidad y Sociedad del Conocimiento (RUSC), 8(2), 197-210.

Mahmud, M. (2012). Facebook does it really work for L2 learners. Academic Research International, 3(2), 357-372.

Muise, A. C. (2009). More information than you ever wanted: Does Facebook bring out the green-eyed monster of jealousy? CyberPsychology \& Behavior, 12, 441-444.

Omar, H. E. (2012). ESL learners' interaction in an online discussion via facebook. Asian Social Science, 8(11), 67-74. 
Kelaniya Journal of Human Resource Management

Volume 10-Number 01-January 2015 \& Number 02-July 2015

Taverner, R. G. (2015). Facebook in teaching:strengths and weaknesses.

The International Journal of Information and Learning Technology, 32(1), 65-78.

Webster, M. (2013). Retrieved from The free dictionary.com:

http://word.com/dictionary/relationship. 